\title{
Widespread osseous metastasis of signet ring type bladder cancer detected by NaF18-PET/ CT bone scan
}

\author{
Aung Zaw Win ${ }^{1}$, Carina Mari Aparici ${ }^{2}$ \\ 1. Dept. Radiology, Nuclear Medicine section, San Francisco Veteran Affairs Medical Center, San Francisco, CA, USA. \\ 2. Dept. Radiology, Nuclear Medicine section, UCSF, San Francisco, CA, USA.
}

Correspondence: Aung Zaw Win. Address: Division of Nuclear Medicine, Department of Radiology, San Francisco VA Medical Center, 4150 Clement Street, San Francisco, CA 94121, USA. Telephone: 1-415-221-4810. Ext. 3051.

Fax: 1-415-7502-142. Email: Aung.Win2@va.gov.

Received: June 8, 2012

DOI : $10.5430 / j b g c . v 2 n 2 p 92$
Accepted: July 4, $2012 \quad$ Published: December 1, 2012

URL: http://dx.doi.org/10.5430/jbgc.v2n2p92

\section{Abstract}

We present a case of a 70 year old black male with innumerable small osseous metastases which were not visible on FDG-PET/CT or CT and were only detected by NaF18-PET/CT bone scan. To our knowledge, this is the first case in the literature reporting the use of NaF18-PET/CT bone scan in the initial staging of signet ring cell bladder carcinoma. Metastatic bone disease was widely spread throughout the skeleton. Some bladder cancers are detected in late stages and have occult distant metastases. Signet ring type adenocarcinomas of the bladder are very rare and they have a very aggressive nature. Proper staging can save the patients from undue surgical procedures. NaF-PET/CT may be a necessary tool in the diagnostic staging of aggressive bladder cancers.

\section{Key words}

Bladder cancer, Signet ring type adenocarcinoma, NaF18-PET/CT, Bone scan, Osseous metastasis

\section{I ntroduction}

Bladder cancer is the fourth most common cancer in men and tenth most common cancer in women ${ }^{[1,2]}$. The incidence is three times higher in men than in women and whites have double the risk compared to blacks ${ }^{[2,3]}$. The overall incidence of bladder cancer is increasing ${ }^{[4]}$. Cigarette smoking contributes as the most common risk for developing bladder cancers ${ }^{[1]}$. The rate of smoking is higher in black males than in white males and the fact that bladder cancer is more prevalent in white males suggest other etiologies for bladder cancer ${ }^{[5]}$. Other known risk factors include exposure to aniline dyes, chronic exposure to cyclophosphamide, the drugs phenacetin and chlornaphazine, bladder stones, and exposure to the parasite Schistosomahaematobium ${ }^{[2,6]}$. Gene mutations have also been implicated in bladder cancer. Receptor-tyrosine kinase-Ras signal transduction pathway mutation and fibroblast growth factor receptor 3 (FGFR3) mutation tend to result in low grade tumors ${ }^{[1]}$. On the other hand, p53, p21, and RB gene mutations can lead to recurrence and distant metastasis $^{[1,7]}$. The median age of diagnosis is 65 years ${ }^{[2]}$.

Over $95 \%$ of bladder cancers in the U.S. are transitional cell type. Other less common types are squamous cell type 3\%, adenocarcinomas $2 \%$ and small cell tumors $<1 \%{ }^{[2]}$. Adenocarcinomas can assume signet ring type histology and the prevalence of this type is only $0.24 \%$ of all primary bladder cancers ${ }^{[8]}$. Signet ring morphology is described as abundant in 
cytoplasm with the nucleus pushed to one side ${ }^{[9]}$. Signet ring cells are most often of gastric, esophageal, ovarian, colorectal and breast origin ${ }^{[10]}$. Moreover, this particular type of bladder carcinoma is associated with advanced stage at presentation, lymph node involvement, and bad prognosis ${ }^{[10]}$. At presentation, $75 \%$ of bladder carcinomas are superficial, $20 \%$ are muscle invasive and $5 \%$ are metastatic ${ }^{[2]}$. The common sites of hematogenous spread are lung, liver, bone and brain ${ }^{[2]}$. Depending on the first site of metastasis, the recurrence rate is different. Bone has a higher recurrence rate than liver or lung ${ }^{[11]}$. Hematuria is the most common but non-specific clinical presentation and occurs in $80-90 \%$ of patients with bladder cancer ${ }^{[2]}$. Still, only $2 \%$ of microscopic hematuria is due to bladder carcinoma ${ }^{[2]}$. Flank pain and bone pain are other non-specific symptoms.

Management of bladder cancer depends on whether the tumor has invaded the muscle wall and whether there is regional lymph node involvement. Superficial tumors can be treated with endoscopic resection. For tumors that have invaded the muscle, radical cystectomy or complete cystectomy approaches can be adopted ${ }^{[12]}$. For metastatic tumors, chemotherapy remains the best treatment option. Combination therapies that are used include methotrexate, vinblastine, doxorubicin, and cisplatin (M-VAC), cisplatin and paclitaxel (PT), gemcitabine and cisplatin (GC), and gemcitabine, paclitaxel, and cisplatin (GTC) ${ }^{[13]}$. Despite the various tratment options, the median survival for patients with bone metastasis is only 9.3 months ${ }^{[2]}$.

\section{Case presentation}

We present the case of a 70 year old black male who presented to the Emergency Department because he was unable to void urine. He had a past medical history of hypertension, diabetes, malaria, post-traumatic stress disorder (PTSD), benign prostatic hypertrophy (BPH), marijuana, cocaine use and exposure to Agent Orange. He smoked half a pack of cigarettes a day for 40 years and he drank socially. The patient's family history is positive for liver cancer and pancreatic cancer. Prior CT scan showed moderate bilateral hydronephrosis with hydroureter and extremely thick-walled bladder. He already had a right nephrostomy tube in place and a new left nephrostomy tube was placed at our hospital. Urinalysis showed microscopic hematuria. Cystoscopy was done and it revealed inflammation inside the bladder. Biopsy samples taken from the cystoscopy revealed bladder carcinoma with signet ring appearance and invasion into the muscularispropria layer. Immunohistochemistry was performed on the tissue samples and the results reveled CK 7+, CK20+, p501S -, mucicarmine +, and p63+. Initial FDG-PET/CT was negative for metastasis. Subsequent NaF18-PET/CT bone scan was ordered and this exam showed innumerable small osseous metastases. Based on the results of the NaF-PET/CT, the bladder tumor was staged as stage IV (T2N2M1). The patient was started on carboplatin and gemcitabine palliative chemotherapy. The patient did not tolerate the treatment well and he died about 6 months after the initial staging.

\section{Discussion}

To our knowledge, this is the first case in the literature reporting the use of NaF18-PET/CT bone scan in the diagnostic staging of signet ring cell type bladder carcinoma. According to our literature search, this is the third case of bladder cancer metastasizing to the right acromion (see Figure 1 ), which is very rare ${ }^{[14,15]}$, although in our case, it was spread throughout the entire axial skeleton. Bladder cancers are more prevalent in whites than in blacks ${ }^{[3]}$ and we report a very rare type of bladder cancer in a black man. Our patient had a 40 year smoking history and this is a major risk factor for developing bladder carcinoma. Hematuria is the most common presentation of bladder cancer ${ }^{[2]}$. Although our patient had microscopic hematuria, his chief complaint was that he was unable to urinate. Other studies had similar findings as ours of CK 7+, p63+ and CK20+ in immunohistochemistry staining of signet ring cells ${ }^{[10,14]}$. Even though our patient had innumerable small bone metastases, he did not have any bone symptoms. He was started on carboplatin and gemcitabine palliative chemotherapy. However, no effective systemic chemotherapy has been established for this subtype of bladder cancer ${ }^{[8]}$. Patients with signet-ring cell carcinoma of the bladder have lower survival rates compared to patients with 
urothelial carcinoma of the bladder ${ }^{[16]}$. Our patient died about 6 months after diagnosis and this is within the predicted range of 9.3 month median survival for bone metastasis patients ${ }^{[2]}$.

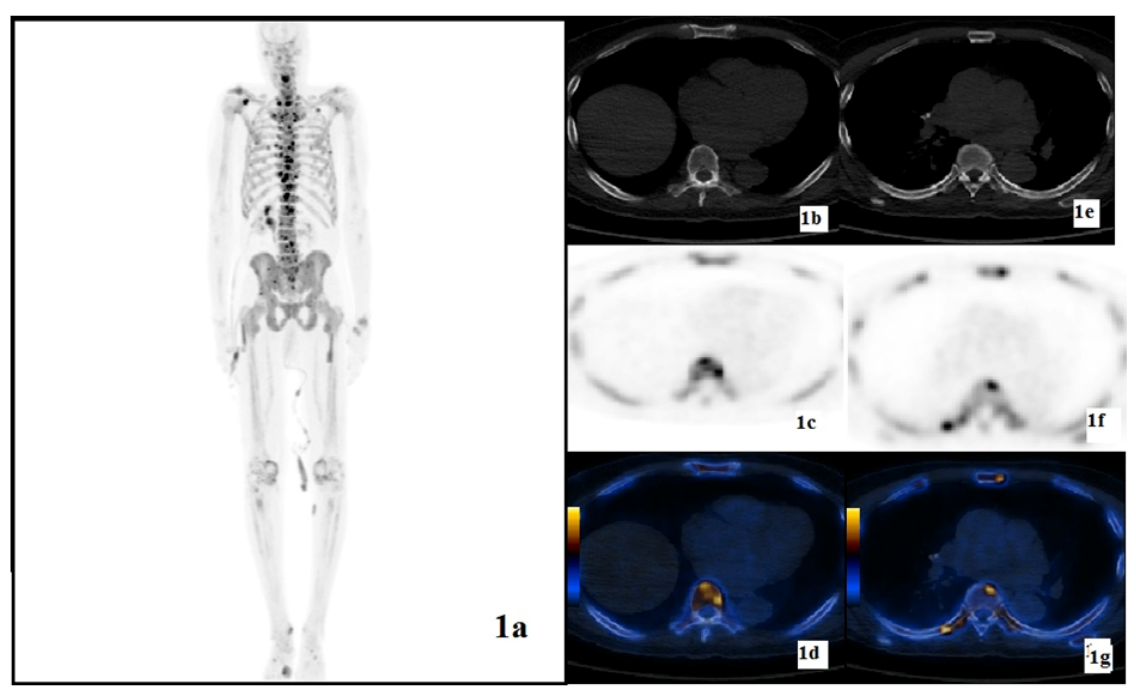

Figure 1. (a) Rotating 3D MIP image from the NaF18-PET/CT bone scan showing innumerable small osteoblastic bony metastases in the axial skeleton including all vertebral bodies, right acromion, bilateral ribs and within the pelvis. (b) Axial CT image, for attenuation correction and antomic localization, shows no bony abnormalities. (c) Same Axial NaF-18 image and (d) NaF 18-PET/CT fusion image showing metastasis on T11 vertebral body. (e) Axial CT image, for attenuation correction and antomic localization, shows no bony abnormalities. (f) Same axial NaF-18 image and (g) NaF18-PET/CT fusion image showing metastases on T9 vertebral body, sternum and right rib.

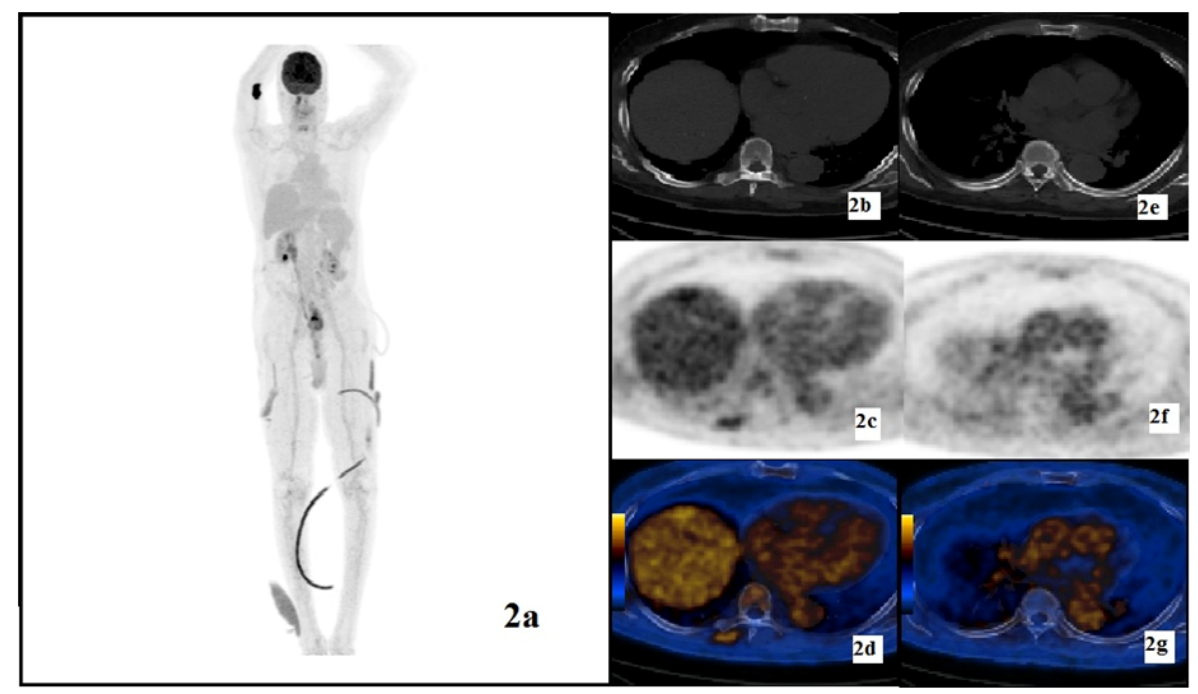

Figure 2. (a) Rotating 3D MIP image from the FDG-PET/CT exam showing no bony metastases. Axial images at the same level as Fig.1b,1c, and 1d. (b) Axial CT image, for attenuation correction and antomic localization, shows no bony abnormalities on T11. (c) Same axial FDG image and (d) FDG-PET/CT fusion image show no bone metastasis on T11. Axial images at the same level as Fig.1e, 1f, and 1g. (e) Axial CT image, for attenuation correction and antomic localization, shows no bony abnormalities on T9, sternum or right rib. (f) Same axial FDG image and (g) FDG-PET/CT fusion image show no bone metastasis on T9, sternum or right rib. 
According to Kibel et al., CT and MRI have low accuracies in detecting metastatic bladder carcinomas ${ }^{[17]}$. Our patient had a CT scan of abdomen and pelvis that did not identify any metastatic bone lesion. About 9 weeks after the CT, our patient had both FDG-PET/CT and NaF18-PET/CT exams (see Figure 1 and 2). NaF18-PET/CT is more sensitive than Tc99m-MDP in detecting bone metastases ${ }^{[18]}$. NaF18-fluoride has double the bone uptake and faster blood clearance than Tc99m labeled phosphonate compounds, and so, it provides a better quality image ${ }^{[19]}$. In our case, FDG-PET/CT (see Figure 2) and diagnostic CT failed to detect the numerous small bone metastases and only the NaF-PET/CT found the bony metastasis. Chakraborty et al. reported a similar experience where they did Tc99m-MDP, FDG-PET/CT and NaF18 PET/CT exams on one patient ${ }^{[19]}$. In their case, FDG-PET/CT and Tc99m-MDP failed to detect the osseous metastases of the bladder cancer and only the NaF18 PET/CT found the bony lesions ${ }^{[19]}$. This further confirms the fact that NaF18-PET/CT bone scan may be the most sensitive imaging test to detect whole body bone metastasis.

Brauers et al. and Taher et al. recommended the use of Tc99m-MDP in the routine diagnostic staging procedure for the muscle invasive bladder cancers ${ }^{[20,21]}$. Based on the experience from our patient and based on the information from the literature, we propose the use of NaF18-PET/CT in the initial workup for bladder cancers. This can save patients from undue surgical procedures such as cystectomies with associated bad quality of life and unjustified financial burdens.

\section{References}

[1] Cheng L, Zhang S, MacLennan GT, et al. Bladder cancer: translating molecular genetic insights into clinical practice. Human Pathology. 2011; 42:455-481. PMid:21106220 http://dx.doi.org/10.1016/j.humpath.2010.07.007

[2] Scher HI, Motzer RJ. Bladder and Renal Cell Carcinomas. In: Kasper DL, Braunwald E, Fauci AS, Hauser SL, Longo DL, Jameson JL eds. Harrison's Principles of Internal Medicine. 16th ed. New York: McGraw-Hill. 2005; 539-540.

[3] Rouprêt M, Zigeuner R, Palou J, et al. Europeanguidelines for the diagnosis and management of upperurinary tracturothelialcellcarcinomas: 2011 update. European Association of Urology Guideline Group for urothelialcellcarcinoma of the upperurinary tract. Actas Urol Esp. 2012; 36: 2-14. PMid:22036956

[4] Shinagare AB, Ramaiya NH, Jagannathan JP, et al. Metastatic Pattern of Bladder Cancer: Correlation With the Characteristics of the Primary Tumor. AJR. 2011; 196:117-122. PMid:21178055 http://dx.doi.org/10.2214/AJR.10.5036

[5] Ries LAG, Harkins D, Krapcho M, et al. SEER Cancer Statistics Review, 1975-2003, National Cancer Institute. Bethesda, MD, http://seer.cancer.gov/csr/1975_2003/, based on November 2005 SEER data submission, posted to the SEER web site, 2006.

[6] Zlotta AR, Cohen SM, Dinney C, et al. BCAN Think Tank session 1: Overview of risks for and causes of bladder cancer. Urol Oncol. 2010; 28: 329-33. PMid:20439032 http://dx.doi.org/10.1016/j.urolonc.2009.10.011

[7] Cote RJ, Dunn MD, Chatterjee SJ, et al. Elevated and absent pRb expression is associated with bladder cancer progression and has cooperative effects with p53. Cancer Res. 1998; 58: 1090-1094. PMid:9515785

[8] Michels J, Barbour S, Cavers D, et al. Metastatic signet-ring cell cancer of the bladder responding to chemotherapy with capecitabine: case report and review of literature. Can Urol Assoc J. 2010; 4: 55-57.

[9] Grignon DJ, Ro JY, Ayala AG, et al. Primary signet-ring cell carcinoma of the urinary bladder. Am J ClinPathol. 1991; 95: 13-20. PMid:1702926

[10] Cimino-Mathews A, Ali SZ. Metastatic Urothelial Carcinoma with Signet Ring Features: Cytomorphologic Findings in Abdominal Paracentesis. Diagnostic Cytopathology. 2010; 39: 132-134.

[11] Volkmer BG, Kuefer R, Bartsch GC. Oncological Followup After Radical Cystectomy for Bladder Cancer-Is There Any Benefit? The Journal of Urology. 2009; 181: 1587-1593. PMid:19233433 http://dx.doi.org/10.1016/j.juro.2008.11.112

[12] Solsona E, Iborra I, Collado A, et al. Feasibility of radical transurethral resection as monotherapy for selected patients with muscle invasive bladder cancer. J Urol. 2010; 184: 475-80. PMid:20620402 http://dx.doi.org/10.1016/j.juro.2010.04.008

[13] Iyer G, Milowsky MI, Bajorin DF. Novel strategies for treating relapsed/refractory urothelial carcinoma. Expert Rev Anticancer Ther. 2010; 10: 1917-32. PMid:21110758 http://dx.doi.org/10.1586/era.10.182

[14] Pasricha S, Hafiz A, Gandhi JS, et al. Urothelial carcinoma of bladder having rhabdoid differentiation with isolated scapular metastasis. J Can Res Ther. 2011; 7: 486-488. PMid:22269416 http://dx.doi.org/10.4103/0973-1482.92008

[15] Forte S, Kos S, Hoffmann A. Unusual location of a urinary bladder cancer metastasis. Case Report. Radiology. $2009 ; 4$ : 316.

[16] Wang J, Wang FW, Kessinger A. The impact of signet-ring cell carcinoma histology on bladder cancer outcome. World J Urol. 2011. http://dx.doi.org/10.1007/s00345-011-0718-8 
[17] Kibel AS, Dehdashti F, Katz MD, et al. Prospective Study of [18F] Fluorodeoxyglucose Positron Emission Tomography/ Computed Tomography for Staging of Muscle-Invasive Bladder Carcinoma. Journal of Clinical Oncology. 2009; 27:4314-4320. PMid:19652070 http://dx.doi.org/10.1200/JCO.2008.20.6722

[18] Win AZ, Aparici CM. Examining the value PSA=10ng/ml as a cutoff for predicting metastatic bone disease in NaF18 PET/CT bone scans, a pilot study. Journal of Biomedical Graphics and Computing. 2012; 2: 57-64. http://dx.doi.org/10.5430/jbgc.v2n1p57

[19] Chakraborty D, Mittal BR, Kamaleshwaran KK, et al. Tc99m-MDP bone scintigraphy, F18-Fluoride PET/CT and F18-FDG PET/CT. Indian J Nucl Med. 2011; 26: 42-43. PMid:21969781

[20] Brauers A, Jung P, Jakse G. Tumor-Adopted Diagnosis of Bladder Cancer. Urol Int. 1999; 63: 22-26. PMid:10592486 http://dx.doi.org/10.1159/000030414

[21] Taher AN, Kotb MH. Bone Metastases in Muscle-Invasive Bladder Cancer. Journal of the Egyptian Nat. Cancer Inst. 2006; 18: 203-208. 